\title{
Perbandingan Ketepatan Ukuran Classic Laryngeal Mask Airway antara Metode Berat Badan dan Lebar Lidah
}

\author{
Abdul Rahman, ${ }^{1}$ Iwan Fuadi, ${ }^{2}$ Iwan Abdul Rachman ${ }^{2}$ \\ ${ }^{1}$ Bagian Anestesi RSUD H. Sahudin Aceh Tenggara, Aceh \\ ${ }^{2}$ Departemen Anestesiologi dan Terapi Intensif \\ Fakultas Kedokteran Universitas Padjadjaran/RSUP Dr. Hasan Sadikin Bandung
}

\begin{abstract}
Abstrak
Classic laryngeal mask airway (CLMA) merupakan alat yang digunakan untuk manajemen jalan napas, baik untuk pengganti ventilasi sungkup wajah maupun intubasi endotrakeal. Pemilihan ukuran yang tepat penting untuk efektivitas penggunaan CLMA. Saat ini pemilihan ukuran berdasar atas metode berat badan. Menurut sebuah studi terbaru metode pengukuran lebar lidah lebik baik daripada metode berat badan. Tujuan penelitian ini adalah mengetahui ketepatan ukuran CLMA antara metode berat badan dan lebar lidah yang dinilai dengan skor fiberoptik dan oropharyngeal leak pressure di RSUP Dr. Hasan Sadikin Bandung. Penelitian ini dilakukan pada bulan Februari 2018 menggunakan uji eksperimental analitik crossection setiap subjek mendapat dua perlakuan yang berbeda antara kedua metode. Uji statistik menggunakan uji chi-square untuk skor fiberoptik dan uji t berpasangan untuk oropharyngeal leak pressure. Hasil penelitian skor fiberoptik lebih optimal daripada metode lebar lidah. Oropharyngeal leak pressure pada metode berat badan rerata $23,00 \pm 1,732 \mathrm{CmH}_{2} 0$ sedangkan metode lebar lidah rerata $19,13 \pm 1,684 \mathrm{CmH}_{2} 0$. Secara statistik diperoleh nilai $\mathrm{p}<0,05$. Simpulan, metode pengukuran lebar lidah adalah alternatif yang mudah dan baik dalam pemilihan ukuran CLMA pasien dewasa.
\end{abstract}

Kata kunci: Classic laryngeal mask airway, pemilihan ukuran CLMA, metode berat badan, metode lebar lidah

\section{Comparison of Classic Laryngeal Mask Airway Size Accuracy between Body Weight Method and Tongue width Method}

\begin{abstract}
Classic laryngeal mask airway (CLMA) is an airway management device that can be used to replace bag valve mask ventilation or endotracheal intubation. Choosing the right size of CLMA is important for the effectiveness of CLMA. Currently, the size of CLMA is selected based on the body weight. However, a recent study suggested that tongue width is a better indicator for size selection than the body weight. The purpose of this study was to assess the accuracy of CLMA size selection using the body weight method and tongue-width method. The assessment was performed using the fiberoptic score and oropharyngeal leak pressure. This was an experimental analytic cross-sectional study conducted in Dr. Hasan Sadikin General Hospital Bandung in February 2018. Each subject in this study received two different treatments using the two methods. The results were analyzed using chi-square for the fiberoptic score and paired t test for the oropharyngeal leak pressure. The fiberoptic score was more optimum when tongue width method was used when compared to the weight method. The oropharyngeal leak pressure in the weight method group was $23.00 \pm 1.732 \mathrm{CmH} 20$ while the pressure in the tongue-width method was $19.13 \pm 1.684 \mathrm{CmH} 20$ (p value $<0.05$ ). In conclusion, the tongue width measurement is an easy and good alternative in the selecting the CLMA size in adult patients.
\end{abstract}

Key words: Classic laryngeal mask airway, size selection CLMA, body weight method, tongue width method

Korespondensi: Abdul Rachman, dr., SpAn, Bagian Anestesi RSUD H. Sahudin Aceh Tenggara, Jl. Raya Kutacane - Blang Kejeran KM 3 Kutacane Aceh Tenggara Indonesia, Kode Pos 24652 Tlpn. 0629-21676, Email bedu_blitz@yahoo.co.id 


\section{Pendahuluan}

Dokter anestesi harus memiliki keterampilan penatalaksanaan jalan napas yang mumpuni. Salah satu alat jalan napas yang sering digunakan pada operasi yang tidak membutuhkan intubasi adalah classic laryngeal mask airway (CLMA) yang telah banyak digunakan untuk menggantikan pipa endotrakeal selama penatalaksaan anestesi, untuk memudahkan ventilasi, dan sebagai jalan untuk memfasilitasi intubasi pipa endotrakeal pada pasien dengan jalan napas sulit. Dalam praktik klinis CLMA sering digunakan karena pemasangannya sederhana. Pemilihan ukuran CLMA harus tepat agar meningkatkan fungsi dan menurunkan risiko komplikasi. Classic laryngeal mask airway dirancang agar sesuai dengan ruang hipofaring. Volume cuff laring yang terlalu besar jika diposisikan di rongga mulut dapat menyebabkan sakit tenggorokan dan kerusakan saraf lingual setelah operasi. Posisi cuff laring yang ideal adalah mengelilingi dasar lidah di bagian superior, sinus piriformis di bagian lateral, dan spingter esofagus bagian atas di bagian inferior. Jika esofagus berada di dalam pinggiran cuff maka akan terjadi distensi lambung dan regurgitasi. Oleh karena itu, pemilihan ukuran yang tepat akan memperbaiki kualitas fungsi serta mengurangi risiko efek samping pada pasien yang akan menjalani operasi. ${ }^{1,2}$

Banyak jurnal dan buku membuktikan kelebihan CLMA yang secara rutin digunakan untuk pemeliharaan jalan napas dalam prosedur pembedahan elektif dengan angka kejadian aspirasi yang tidak signifikan dan dapat digunakan sebagai perangkat penyelamatan dalam pengelolaan jalan napas sulit. Kejadian komplikasi tersebut cukup rendah, akan tetapi beberapa komplikasi dapat menyebabkan morbiditas. Komplikasi yang serius termasuk cedera pada faring, pneumomediastinum, mediastinitis, atau dislokasi aritenoid. Komplikasi ringan yang sering dilaporkan seperti sakit tenggorokan pascaoperasi, disfagia, nyeri saat menelan, atau suara serak. Komplikasi yang mungkin terjadi tersebut sering disebabkan oleh kerusakan saraf kranial yang terdapat pada daerah faring dan laring., ${ }^{3,4}$

Beberapa peneliti telah melaporkan metode untuk memilih CLMA dengan ukuran yang tepat. ${ }^{4-7}$. Penelitian-penelitian tersebut masih menunjukkan hubungan yang tidak konsisten antara ukuran dan jenis kelamin, berat badan, tinggi badan, indeks massa tubuh, serta ukuran atau bentuk dari hipofaring CLMA ditempatkan. Pada saat ini sering dilakukan pemilihan ukuran dengan ukuran yang sudah disediakan produsen berdasar atas metode berat badan. Metode ini dianggap sederhana, mudah dan cepat, namun metode tersebut hanya bersifat subjektif dan belum diketahui sejauh mana ketepatan posisi tersebut di sekitar hipofaring untuk mengurangi komplikasi. Berdasar atas kondisi tersebut maka diperlukan metode baru yang lebih objektif, sederhana, murah, dan mudah diaplikasikan dalam praktik sehari-hari.

Pemilihan ukuran CLMA yang sesuai dapat mencegah kebocoran di sekitar orofaring selama pemberian tekanan ventilasi positif dan mencegah terjadi iskemik pada organ di sekitar hipofaring akibat tekanan cuff yang berlebihan. Sebelumnya, pemilihan ukuran disarankan harus berdasar atas jenis kelamin (ukuran 5 untuk laki-laki dan ukuran 4 untuk perempuan). Classic laryngeal mask airway yang tidak ditempatkan secara benar mungkin tidak selalu terdeteksi secara klinis, posisi yang tidak tepat dapat meningkatkan volume isi lambung yang dapat menyebabkan aspirasi terutama jika pasien dengan ventilasi terkontrol. ${ }^{8,9}$

Beberapa hasil penelitian menemukan ketepatan letak CLMA masih kurang baik berdasar atas pemilihan ukuran berat badan yang dinilai dengan skor fiberoptik. Pada penelitian yang dilakukan di Taiwan menemukan bahwa pemilihan ukuran CLMA berdasar atas lebar lidah lebih baik daripada metode berdasar atas berat badan. Diperlukan penelitian lebih banyak untuk mencari metode yang terbaik dalam penentuan ukuran CLMA yang digunakan serta perubahan pedoman jika diperlukan. Skor fiberoptik merupakan gold standard yang dapat digunakan untuk 
menentukan letak posisi CLMA yang akurat di hipofaring. ${ }^{9,10}$

Penelitian ini adalah penelitian ulangan yang bertujuan mengetahui perbedaan ketepatan ukuran CLMA antara metode berat badan dan lebar lidah yang dinilai dari skor fiberoptik dan oropharyngeal leak pressure.

\section{Subjek dan Metode}

Penelitian ini merupakan penelitian eksperimental dengan desain cross section study atau metode potong lintang prospektif. Subjek penelitian adalah pasien dewasa yang terjadwal elektif one day surgery yang membutuhkan pemasangan CLMA.

Kriteria inklusi subjek penelitian ini adalah usia 18-60 tahun, pasien menjalani pembedahan dengan anestesi umum, kooperatif, dan Mallampati I-II. Kriteria eksklusi, yaitu indeks massa tubuh lebih dari 30, trauma pada daerah wajah, buka mulut kurang dari 3 jari pasien, dan kelainan anatomi seperti lidah besar, leher pendek, micrognathia, serta prognatishme.

Penentuan besar sampel dilakukan berdasar atas perhitungan statistik dengan rumus uji hipotesis beda rata-rata dengan taraf nyata 95\% dan kekuatan uji 90\% serta diperoleh besar sampel minimal sebanyak 15 sampel dengan 2 perlakuan yang berbeda. Perlakuan I mendapatkan pemilihan CLMA dengan metode berat badan dan perlakuan II mandapatkan pemilihan CLMA dengan metode lebar lidah. Kedua perlakuan pasien dilakukan penilaian skor fiberoptik dan oropharyngeal leak pressure sesaat setelah pemasangan CLMA. Teknik pengambilan sampel dengan consecutive sampling dan subjek mendapat dua perlakuan dengan urutan perlakuan ditentukan secara random menggunakan metode lempar koin.

Penelitian ini dilakukan di Rumah Sakit Umum Pusat Dr. Hasan Sadikin Bandung pada bulan Februari 2018 setelah mendapatkan persetujuan Komite Etik Penelitian Kesehatan Fakultas Kedokteran Universitas Padjadjaran/ RSHS. Data mengenai karakteristik pasien, berat badan dan lebar lidah diambil dari pasien yang berada di ruang pemeriksaan Preoperatif Rumah Sakit Dr. Hasan Sadikin Bandung.

Peralatan terdiri atas CLMA merk WORK ${ }^{\circledR}$, fiberoptik merk Storz 8403 ZX monitor $^{\circledR}$, timbangan OMRON ${ }^{\circledR}$ digital HN 289 BLU, cuff inflator PORTEX ${ }^{\circledR}$, stetoskop Litman ${ }^{\circledR}$, Nihon Kohden Monitor BSM-3763 ${ }^{\circledR}$, pengukur lebar lidah yang disesuaikan dengan ukuran CLMA (Gambar 1; Tabel 1).

Pemilihan ukuran CLMA berdasar atas metode berat badan menggunakan ukuran yang direkomendasikan produsen (ukuran 3: $30-50 \mathrm{~kg}$, ukuran 4: 50-70 kg, ukuran 5 : $>70 \mathrm{~kg}$ ). Pemilihan ukuran CLMA berdasar atas metode lebar lidah dilakukan dengan membuat tiga penggaris dalam centimeter dengan lebar yang berbeda sesuai ukuran CLMA seperti yang dapat dilihat pada Tabel 1. Lebar tiap-tiap penggaris ditentukan oleh lebar terpanjang CLMA dengan balon cuff inflasi minimal. Pasien diminta untuk membuka mulut dan menjulurkan lidahnya dengan santai. Ukuran CLMA ditentukan oleh penggaris yang memiliki lebar yang sama seperti lidah.

Di kamar operasi pasien berbaring terlentang, dipasang alat pemantauan tanda vital pada tubuh pasien, dan dicatat data awal. Induksi anestesi dilakukan dengan pemberian fentanil $2 \mu \mathrm{g} / \mathrm{kgBB}$ dan propofol $2 \mathrm{mg} / \mathrm{kgBB}$. Setelah pasien tertidur diberikan pelumpuh otot atrakurium $0,5 \mathrm{mg} / \mathrm{kgBB}$. Setelah onset atrakurium tercapai $( \pm 3$ menit $)$ dilakukan pemasangan CLMA. Semua insersi dilakukan oleh pengguna CLMA berpengalaman dengan menggunakan teknik triple airway manoeuvre atau teknik insersi dua orang. Setelah insersi, cuff dikembangkan dengan udara hingga tekanan $60 \mathrm{cmH}_{2} \mathrm{O}$.

Oropharyngeal leak pressure diukur dengan manometer yang ditempelkan pada ujung valve inflation CLMA, kemudian stetoskop diletakkan di lateral tiroid untuk mendengar suara gurgling di sekitar orofaring. Tekanan pada cuff dikurangi dengan manometer sampai terdengar suara gurgling, kemudian tekanan cuff ditambahkan sedikit sampai suara gurgling hilang dan pada kondisi tersebut dinyatakan oropharyngeal leak pressure stabil 


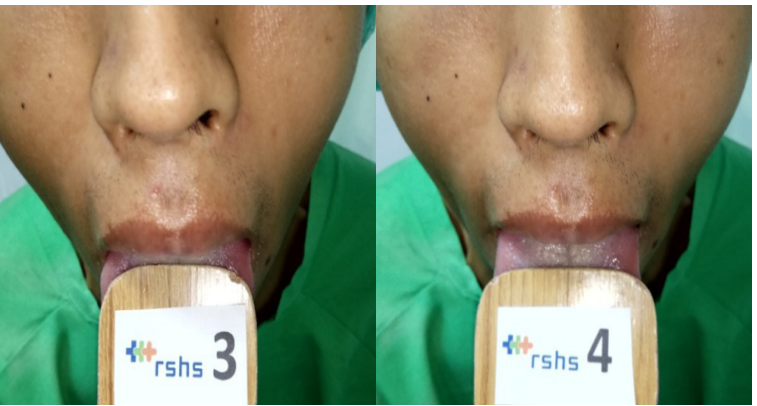

Gambar 1 Penggaris Pengukur Lebar Lidah Dikutip dari: Dokumen Pribadi

dan dicatat tekanannya.

Ketepatan letak CLMA di hipofaring dilihat dengan menggunakan fiberoptik dan diberikan skor dengan dinilai sebagai berikut: 4 = hanya terlihat pita suara; $3=$ pita suara dan bagian posterior dari epiglottis yang terlihat; 2 = pita suara dan anterior epiglotis yang terlihat; dan $1=$ pita suara tidak terlihat. Setelah penilaian, CLMA pertama dilepaskan dan CLMA kedua dimasukkan, pasien diventilasi dengan oksigen menggunakan sungkup wajah selama 5 menit dan diberikan tambahan propofol $1 \mathrm{mg} / \mathrm{kgBB}$. Penilaian insersi CLMA kedua adalah sama dengan CLMA pertama. Pasien diberikan rumatan sevofluran dan pernapasan spontan dijaga selama operasi. Dua parameter yang dicatat, yaitu skor fiberoptik, dan oropharyngeal leak pressure kedua metode.

Uji statistik pada penelitian ini memakai uji chi-square untuk skor fiberoptik dan uji-t berpasangan untuk oropharyngeal leak pressure. Data hasil penelitian dicatat dan diolah menggunakan program statistical product and service solution (SPSS) versi 24.0 for windows.

\section{Hasil}

Pada penelitian ini tiap subjek mendapatkan

\section{Tabel 1 Lebar Penggaris sesuai ukuran CLMA}

\begin{tabular}{lccc}
\hline Ukuran CLMA & 3 & 4 & 5 \\
Lebar $(\mathrm{cm})$ & 5 & 5,7 & 6,5 \\
\hline
\end{tabular}

Dikutip dari: Huang dan Cherng ${ }^{10}$
Tabel 2 Karakteristik Subjek Penelitian

\begin{tabular}{lc}
\hline \multicolumn{1}{c}{ Variabel } & $\mathbf{n}=\mathbf{1 5}$ \\
\hline Usia (tahun) & \\
Mean \pm Std & $41,46 \pm 9,341$ \\
Median & 46,00 \\
Range (min.-maks.) & $24,00-54,00$ \\
Berat badan (kg) & \\
Mean \pm Std & $64,16 \pm 8,789$ \\
Median & 65,80 \\
Range (min.-maks.) & $51,20-81,70$ \\
Tinggi badan (cm) & $161,80 \pm 8,282$ \\
Mean \pm Std & 161,00 \\
Median & $147,00-175,00$ \\
Range (min.-maks.) & \\
BMI (kg/m ${ }^{2}$ ) & $24,92 \pm 2,840$ \\
Mean \pm Std & 24,00 \\
Median & $20,00-29,10$ \\
Range (min.-maks.) & \\
\hline
\end{tabular}

Keterangan: untuk data kategorik disajikan dengan jumlah/frekuensi dan persentase, sedangkan data numerik disajikan dengan rerata, median standar deviasi dan range

dua perlakuan berbeda sehingga gambaran karakeristik subjek penelitian pada kedua kelompok berdasar atas usia, berat badan, tinggi badan, dan indeks massa tubuh dipastikan tidak ada perbedaan (Tabel 2).

Dari seluruh pasien yang diteliti, tiap-tiap pasien memiliki ukuran CLMA yang berbeda di antara kedua metode. Ukuran CLMA yang ditentukan dengan metode lebar lidah lebih kecil dibanding dengan ukuran CLMA yang ditentukan dengan metode berat badan (Tabel 3).

Pada pemeriksaan skor fiberoptik didapatkan skor optimal (skor 4) lebih didominasi pada metode lebar lidah dibanding dengan metode berat badan dan perbedaan sangat bermakna $(\mathrm{p}<0,05$; Tabel 4$)$.

Oropharyngeal leak pressure didapatkan lebih rendah pada metode lebar lidah dibanding dengan metode berat badan dengan perbedaan yang sangat bermakna $(p<0,001$; Tabel 5). 
Tabel 3 Perbedaan ukuran CLMA antara Kedua Metode

\begin{tabular}{cccc}
\hline Pasien & $\begin{array}{c}\text { Berat Badan } \\
\text { (kg) }\end{array}$ & $\begin{array}{c}\text { Ukuran CLMA } \\
\text { Metode Berat Badan }\end{array}$ & $\begin{array}{c}\text { Ukuran CLMA } \\
\text { Metode Lebar Lidah }\end{array}$ \\
\hline 1 & 67,9 & 4 & 3 \\
2 & 68,1 & 4 & 3 \\
3 & 56,5 & 4 & 3 \\
4 & 60,5 & 4 & 3 \\
5 & 72,1 & 5 & 4 \\
6 & 68,7 & 4 & 3 \\
7 & 54,6 & 4 & 3 \\
8 & 65,8 & 4 & 3 \\
9 & 72,4 & 5 & 3 \\
10 & 81,7 & 5 & 3 \\
11 & 71,8 & 5 & 3 \\
12 & 61,5 & 4 & 3 \\
13 & 51,8 & 4 & 3 \\
14 & 57,8 & 4 & 3 \\
15 & 51,2 & 4 & 3 \\
\hline
\end{tabular}

\section{Pembahasan}

Usia rerata pasien adalah $41,46 \pm 9,341$ tahun. Variasi usia berpengaruh secara tidak langsung terhadap anatomi jalan napas. Penelitian yang dilakukan sebelumnya pada anak dengan menggunakan skor fiberoptik menunjukkan angka kejadian malposisi letak CLMA yang tinggi dan hanya diperoleh $12-50 \%$ posisi yang ideal. Penelitian yang dilakukan pada 50 pasien geriatrik diidentifikasi letak CLMA dengan skor fiberoptik dengan penempatan yang tepat sebesar 29,2\%. Perbedaan anatomi jalan napas antara anak, dewasa, dan geriatrik berperan penting dalam penilaian ketepatan ukuran CLMA. ${ }^{11}$ hal tersebut menjadi dasar bagi peneliti yang menjadikan pasien dewasa sebagai subjek agar penelitian menjadi homogen.

Indeks massa tubuh berpengaruh terhadap struktur anatomis wajah. Pasien obesitas memiliki jumlah jaringan lemak yang besar yang dapat digambarkan dari rasio lingkar leher (NC) dan jarak tiromental (TM). Hal ini

Tabel 4 Skor Fiberoptik antara Kedua Metode

\begin{tabular}{cccc}
\hline \multirow{3}{*}{ Skor Fiberoptik } & \multicolumn{2}{c}{ Kelompok } & \multirow{2}{*}{ Nilai p } \\
\cline { 2 - 3 } & Metode Berat Badan & Metode Lebar Lidah & \\
\cline { 2 - 3 } & $\mathbf{n = 1 5}$ & $\mathbf{n = 1 5}$ & \\
\hline 1 & 3 & 0 & \multirow{2}{*}{$\mathbf{0 2 8}^{* *}$} \\
3 & 4 & 2 & \\
4 & 6 & 3 & \\
\hline
\end{tabular}

Keterangan: untuk data numerik nilai p diuji dengan uji chi-square apabila data berdsitribusi normal dengan alternatif uji Kolmogorov Smirnov apabila data tidak berdistribusi normal. Nilai kemaknaan berdasar atas nilai $\mathrm{p}<0,05$. Tanda* menunjukkan nilai $\mathrm{p}<0,05$ artinya signifkan atau bermakna secara statistik 
Tabel 5 Oropharyngeal Leak Pressure $\left(\mathrm{CmH}_{2} \mathrm{0}\right)$ antara Kedua Metode

\begin{tabular}{|c|c|c|c|}
\hline \multirow{3}{*}{$\begin{array}{c}\text { Oropharyngeal Leak } \\
\text { Pressure }\left(\mathrm{CmH}_{2} \mathrm{0}\right)\end{array}$} & \multicolumn{2}{|c|}{ Kelompok } & \multirow{3}{*}{ Nilai p } \\
\hline & Metode Berat Badan & Metode Lebar Lidah & \\
\hline & $\mathrm{N}=15$ & $\mathrm{~N}=15$ & \\
\hline Mean \pm Std & $23,00 \pm 1,732$ & $19,13 \pm 1,684$ & \\
\hline Median & 23,00 & 19,00 & $<0,001$ \\
\hline Range (min.-maks.) & $20,00-26,00$ & $17,00-22,00$ & \\
\hline
\end{tabular}

memberikan pengaruh terhadap kesulitan pemasangan alat bantu napas. Insidens kesulitan pemasangan alat bantu napas pada pasien obesitas dengan indeks massa tubuh di atas 30 telah dilaporkan pada beberapa kasus. ${ }^{12}$ Pada penelitian ini indeks massa tubuh rerata $24,92 \pm 2,840$.

Konfirmasi letak CLMA secara sederhana biasa dilakukan dengan auskultasi suara napas dan tidak terdengar suara di epigastrium, observasi kenaikan dinding dada dengan ventilasi, dan end-tidal carbon dioxide $\left(\mathrm{EtCO}_{2}\right)$. Ketepatan anatomi yang akurat pada CLMA akan menghasilkan fungsi yang lebih baik. Pemeriksaan ketepatan letak CLMA menggunakan fiberoptik adalah cara konfirmasi yang paling tepat (gold standard). Hal ini karena posisi CLMA intraoral dan skor fiberoptik dapat dinilai langsung. ${ }^{13,14}$

Dalam praktik klinis, letak CLMA harus sesuai dengan anatomi jalan napas. Beberapa hasil penelitian menemukan ketepatan letak CLMA masih kurang baik bila pemilihan berdasar atas ukuran berat badan yang dinilai dengan skor fiberoptik. ${ }^{10,11,14}$ Penelitian tersebut masih menunjukkan hubungan yang tidak konsisten antara ukuran CLMA dan jenis kelamin, berat badan, tinggi badan, indeks massa tubuh bila CLMA ditempatkan pada rongga hipofaring.

Penelitian yang dilakukan di Turki menggunakan pemilihan ukuran CLMA dengan metode berat badan pada 59 orang pasien didapatkan bahwa ketepatan letak CLMA dengan nilai skor fiberoptik, hasilnya sebesar 49,2\% memiliki skor 1 (pita suara tidak terlihat) dan hanya 1,7\% yang memiliki skor 4 (hanya pita suara yang terlihat). ${ }^{14}$ Namun, berbeda dengan penelitian yang dilakukan di Taiwan yang membuktikan bahwa terdapat perbedaan bermakna dalam pemilihan ukuran CLMA antara metode berat badan dan lebar lidah. Pada penelitian terhadap 21 pasien yang ditentukan secara acak tersebut, didapatkan bahwa metode berat badan memiliki skor fiberoptik rerata $2,23 \pm 0,83$, sedangkan metode lebar lidah memiliki skor rerata $3,38 \pm 0,74 .^{10}$

Classic laryngeal mask airway membentuk pelindung pada jalan napas di hipofaring yang memiliki celah di permukaan anterior yang menutupi introitus laring dan posisi ideal CLMA di bagian superior adalah di dasar lidah. ${ }^{1,11,13}$ Posisi airway tube (pipa) CLMA berada di sepanjang orofaring posterior, palatum mole, palatum durum, dan gigi. Idealnya epiglotis akan tertekan oleh balon cuff di bagian posterior CLMA yang berbatasan dengan dasar lidah sehingga bila dilihat dengan fiberoptik hanya terlihat pita suara (skor 4). ${ }^{1,13,15}$

Pada penelitian ini didapatkan metode lebar lidah memiliki rerata skor fiberoptik yang lebih baik dibanding dengan metode berat badan (Tabel 4).

Metode lain yang sering digunakan dan cukup baik untuk menilai penempatan CLMA adalah dengan menguji apakah terjadi kebocoran saat CLMA diberi udara dengan tekanan tertentu atau dikenal dengan uji oropharyngeal leak pressure (OLP). Oropharyngeal leak pressure adalah tekanan saat kebocoran udara terjadi di sekitar 
CLMA. Oropharyngeal leak pressure menjadi indikator derajat proteksi saluran napas dan menentukan apakah ventilasi tekanan positif dapat diberikan. Manfaat lain OLP adalah melakukan konfirmasi posisi CLMA secara noninvasif. ${ }^{15}$

Hasil analisis oropharyngeal leak pressure pada Tabel 3 didapatkan bahwa metode berat badan memiliki oropharyngeal leak pressure lebih besar dibanding dengan metode pengukuran lebar lidah dengan perbedaan yang bermakna. Dari penelitian sebelumnya di Taiwan dinyatakan bahwa oropharyngeal leak pressure lebih rendah dengan pemilihan ukuran metode lebar lidah dibanding dengan metode pemilihan berdasar atas berat badan. ${ }^{10}$

Berdasar atas teori hukum Boyle, volume gas berbanding terbalik dengan tekanan asalkan suhu tetap konstan. Industri endotrakeal tube telah menggantikan desain balon dari high pressure low volume menjadi low pressure high volume yang bertujuan mencegah terjadi iskemik di daerah orofaring. Pemasangan CLMA yang terlalu kecil dapat menyebabkan kebocoran dan peningkatan cuff pressure agar dapat menempati rongga orofaring. Jika CLMA terlalu besar juga tidak akan menyelesaikan masalah dan justru dapat menyebabkan pergeseran letak CLMA setelah volume cuff dikembangkan. Kita mengharapkan pressure yang rendah dan volume cuff yang cukup sehingga risiko komplikasi tidak terjadi. Penelitian ini membuktikan bahwa keberadaan balon cuff di hipofaring yang ideal memiliki pressure yang rendah pada metode lebar lidah.

Ketidaknyamanan pasien pada penelitian ini disebabkan pada saat dilakukan pengukuran lebar lidah pasien diminta menjulurkan lidahnya dengan rilek/santai.

\section{Simpulan}

Ketepatan ukuran CLMA berdasar atas metode lebar lidah memiliki letak posisi yang optimal dinilai dengan skor fiberoptik dan menghasilkan oropharyngeal leak pressure yang lebih rendah dibanding dengan metode berat badan sehingga metode lebar lidah dapat menjadi alternatif yang mudah dan baik dalam pemilihan ukuran CLMA pada pasien dewasa. Saran perlu dilakukan penelitian lebih lanjut mengenai perbandingan ketepatan pemilihan ukuran CLMA dengan metode pengukuran lebar lidah untuk berbagai macam jenis CLMA yang lain.

\section{Daftar Pustaka}

1. Morgan GE, Mikhail MS. Airway management. Dalam: Butterworth JF, Mackey DC, Wasnick JD, penyunting. Morgan \& Mikhail's clinical anesthesiology. Edisi ke-5. USA: McGraw-Hill Companies; 2011. hlm. 317-40.

2. Van Putte CL, Regan JL, Russo AF. Respiratory system. Seeley's essential anatomy and physiology. Edisi ke-9. New York: McGraw-Hill; 2016. hlm. 412-6.

3. Hernandez MR, Klock PA Jr, Ovassapian A. Evolution of the extraglottic airway: a review of its history, applications, and practical tips for success. Anesth Analg. 2012;114(2):349-68.

4. Van Zundert, Gatt SP, Kumar CM. Failed supraglottic airway: an algorithm for suboptimally placed supraglottic airway devices based on videolaryngoscopy. $\mathrm{Br} \mathrm{J}$ Anaesth. 2017;118(5):645-9.

5. Thiruvenkatarajan V, Van Wijk RM, Rajbhoj A. Cranial nerve injuries with supraglottic airway devices: a systematic review of published case reports and series. Anaesthesia. 2015;70:344-59.

6. Michalek P, Donaldson W, Vobrubova E, Hakl M. Complications associated with the use of supraglottic airway devices in perioperative medicine. Biomed Res Int. 2015;2015:746560.

7. Ramaiah R, Das D, Bhananker S M, Joffe A M. Extraglottic airway devices: a review. Int J Crit Ill Inj Sci. 2014;4(1):77-87.

8. Tang Yee M, Tang Ping I, Wang Yin C. Optimal size AMBU laryngeal mask airway among Asian adult population. Med J Malaysia. 2014;69(4):151-5.

9. Atef HM, El Tabakh MT. Fiber-optic evaluation of laryngeal mask airway 
position during controlled mechanical ventilator: time effect. Egypt J Anaesth. 2014;17:1-7.

10. Huang $\mathrm{YH}$, Cherng $\mathrm{CH}$. Optimal size selection of the classic laryngeal mask airway by tongue width-based method in male adults. J Chin Med Assoc. 2014;77(8):422-5.

11. Kim EM, Kim MS, Koo BN. Clinical efficacy of the classic laryngeal mask airway in elderly patients: a comparison with young adult patients. Korean J Anaesthesiol. 2015;68(6):568-74.

12. Budde AO, Desciak M, Reddy V, Falcucci OA, Vaida SJ, Pott LM. The prediction of difficult intubation in obese patients using mirror indirect laryngoscopy: a prospective pilot study. Anaesthesiol Clin Pharmacol. 2013;29(2):183-6.

13. Bose N. Laryngeal mask airway insertion. Dalam: Gurjar M, penyunting. Manual of ICU procedures. Edisi ke-1. India: Jaypee The Health Sciences Publisher; 2015. hlm. 30-46.

14. Polat R, Aydin GB, Ergil J, Sayin M. Comparison of the i-gel and the laryngeal mask classic in terms of clinical performance. Rev Bras Anestesiol. 2015;65(5):343-8.

15. Van Zundert AAJ, Kumar CM, Van Zundert CRV. Malpositioning of supraglottic airway devices: preventive and corrective strategies. Br J Anaesth. 2016;116(5):57982. 